\title{
Prefibrillar Amyloid Aggregates Could Be Generic Toxins in Higher Organisms
}

\author{
Serena Baglioni, ${ }^{1}$ Fiorella Casamenti, ${ }^{2}$ Monica Bucciantini, ${ }^{1,3}$ Leila M. Luheshi, ${ }^{4}$ Niccolò Taddei,,${ }^{1,3}$ Fabrizio Chiti, ${ }^{1}$ \\ Christopher M. Dobson, ${ }^{4}$ and Massimo Stefani ${ }^{1,3}$ \\ ${ }^{1}$ Department of Biochemical Sciences, University of Florence, 50134 Florence, Italy, ${ }^{2}$ Department of Pharmacology, University of Florence, 50139 Florence, \\ Italy, ${ }^{3}$ Interuniversity Centre for the Study of the Molecular Basis of Neurodegenerative Diseases and ${ }^{4}$ Department of Chemistry, University of Cambridge, \\ Cambridge CB2 1EW, United Kingdom
}

More than 40 human diseases are associated with fibrillar deposits of specific peptides or proteins in tissue. Amyloid fibrils, or their precursors, can be highly toxic to cells, suggesting their key role in disease pathogenesis. Proteins not associated with any disease are able to form oligomers and amyloid assemblies in vitro displaying structures and cytotoxicity comparable with those of aggregates of diseaserelated polypeptides. In isolated cells, such toxicity has been shown to result from increased membrane permeability with disruption of ion homeostasis and oxidative stress. Here we microinjected into the nucleus basalis magnocellularis of rat brains aggregates of an Src homology 3 domain and the N-terminal domain of the prokaryotic HypF, neither of which is associated with amyloid disease. Prefibrillar aggregates of both proteins, but not their mature fibrils or soluble monomers, impaired cholinergic neuron viability in a dose-dependent manner similar to that seen in cell cultures. Contrary to the situation with cultured cells, however, under our experimental conditions, cell stress in tissue is not followed by a comparable level of cell death, a result that is very likely to reflect the presence of protective mechanisms reducing aggregate toxicity. These findings support the hypothesis that neurodegenerative disorders result primarily from a generic cell dysfunction caused by early misfolded species in the aggregation process.

Key words: amyloid fibrils; cell dysfunction; neurodegenerative diseases; protein aggregation; protein misfolding; aggregate microinjection

\section{Introduction}

The deposition of aggregates of peptides or proteins in specific organs or tissues is a key event in the pathogenesis of many degenerative diseases (Huff et al., 2003; Selkoe, 2003; Stefani and Dobson, 2003). Such species, or their precursors, can be highly cytotoxic, suggesting that they could play crucial roles in disease pathogenesis (Conway et al., 2000; Goldberg and Lansbury, 2000; Nilsberth et al., 2001; Bucciantini et al., 2002). In particular, disorders such as Alzheimer's disease and type II diabetes are characterized by the presence in the affected tissues of proteinaceous fibrillar deposits (Kelly, 1998; Merlini and Westermark, 2004; Selkoe, 2004). Such fibrils and their precursors result from polypeptide chain misfolding, leading to the formation of ordered polymeric assemblies built around a core of $\beta$-sheet structure (Serpell et al., 2000; Tycko, 2004).

\footnotetext{
Received Nov. 9, 2005; revised May 29, 2006; accepted May 31, 2006

This work was supported by Ministero dell'Istruzione, dell'Università, e della Ricerca Grants 2003054414_002, 2002058218_001, and RBNE01S29H_004, by programme grants (C.M.D.) from the Wellcome Trust, and by the Leverhulme Trust. L.M.L. acknowledges a studentship from Merck Sharp and Dohme and support from Downing College (Cambridge, UK). We are grateful to Dr. D. Nosi for valuable help in obtaining confocal microscopy images and Dr. Arianna Bellucci and Dr. Ilaria Luccarini for their support in the animal experiments.

Correspondence should be addressed to either of the following: Prof. Massimo Stefani, Department of Biochemical Sciences, University of Florence, Viale Morgagni 50, 50134 Florence, Italy, E-mail: stefani@scibio.unifi.it; or Prof Christopher M. Dobson, Department of Chemistry, University of Cambridge, Lensfield Road, Cambridge CB2 1EW, UK, E-mail: cmd44@cam.ac.uk.

D0I:10.1523/JNEUROSCI.4809-05.2006

Copyright $\odot 2006$ Society for Neuroscience $\quad$ 0270-6474/06/268160-08\$15.00/0
}

Until recently, the ability to form amyloid structures was considered to be an unusual property of the polypeptide chains found in the deposits associated with the various amyloid diseases. However, an increasing number of proteins and peptides, even those with as few as four residues and amino acid homopolymers, have been shown to aggregate in vitro into fibrillar structures closely similar to those formed in amyloid disease (Guijarro et al., 1998; Chiti et al., 2001; Fändrich and Dobson, 2002) (for review, see Stefani and Dobson, 2003). Experiments have also shown that these aggregates, particularly in their prefibrillar forms, can show a level of toxicity to cultured cells analogous to that of aggregates of disease-associated peptides and proteins (Bucciantini et al., 2002; Kranenburg et al., 2003; Sirangelo et al., 2004). These toxic effects have been shown to result from perturbations to fundamental biochemical parameters of cells such as free $\mathrm{Ca}^{2+}$ levels and redox status (Stefani and Dobson, 2003; Bucciantini et al., 2004). Accordingly, it has been suggested that the ability to form amyloid fibrils is a generic property of polypeptide chains (summarized by Stefani and Dobson, 2003) and that cytotoxicity could be a common feature of the misfolded species that are the universal precursors to the fibrillar structures (Bucciantini et al., 2002; Kayed et al., 2003, 2004; Kranenburg et al., 2003).

Toxic aggregates can overwhelm the intracellular defense machineries of isolated cells, including the unfolded protein response in the endoplasmic reticulum and the heat shock response 

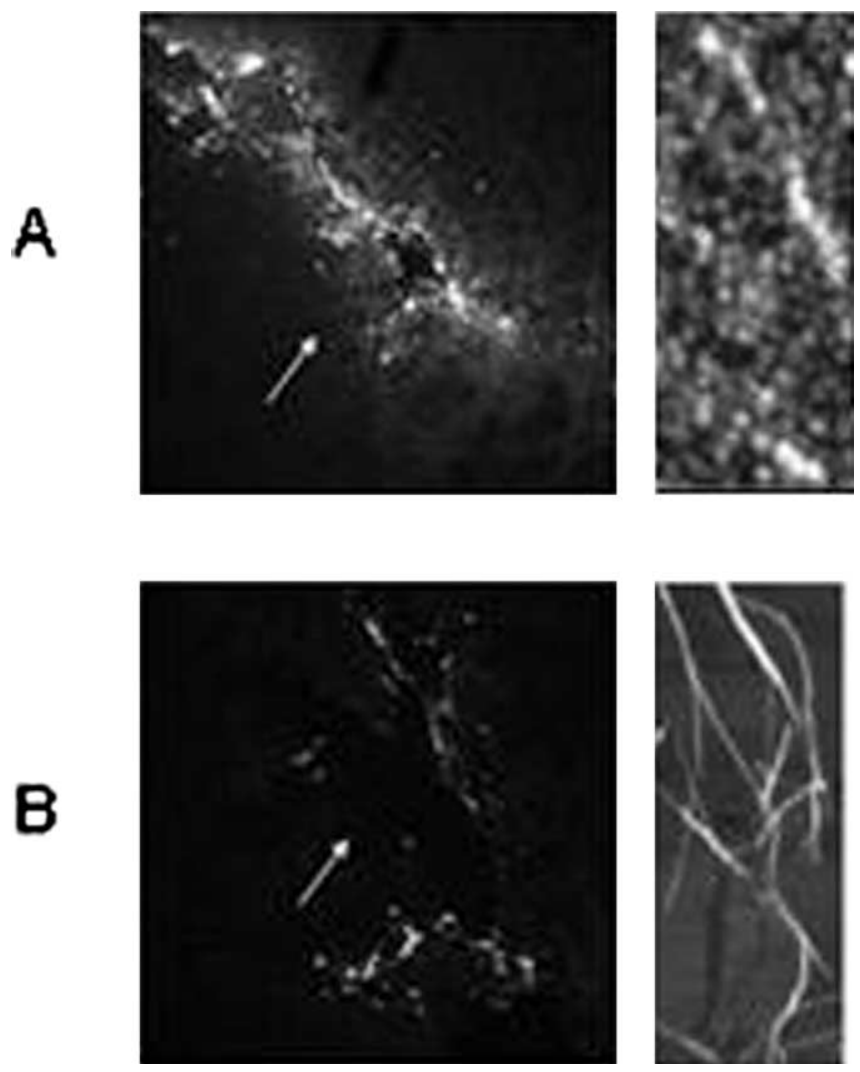

Figure 1. Confocal microscopy images of the NBM from rats at the sites of microinjection. The presence of prefibrillar $(\boldsymbol{A})$ and fibrillar $(\boldsymbol{B})$ aggregates of HypF-N labeled with the fluorescent dye Texas Red is shown (10× magnification in each case). Images were taken $24 \mathrm{~h}$ after injection. For technical details, see Materials and Methods. Right panels show atomic force microscopy images of the two types of injected aggregates [kindly provided by A. Relini (University of Genoa, Genoa, Italy) and obtained as reported previously (Relini et al., 2004)].

in the cytosol (Goldberg, 2003; Sitia and Braakman, 2003); however, it is not yet clear whether they can also overcome the additional protective mechanisms that are present in higher organisms to maintain cell viability. These mechanisms include immune cells, macrophages, and the glia of the CNS, together with specific trophisms that are endogenous to specific tissues. The objective of our investigation was to compare the effects produced by different types of aggregates of different types of proteins to cells in tissue. To address this issue, we microinjected into the nucleus basalis magnocellularis (NBM) of rat brains prefibrillar or fibrillar aggregates of the N-terminal domain of $\mathrm{HypF}$ (HypF-N) or phosphatidylinositol-3-kinase Src homology 3 $\left(\mathrm{PI}_{3} \mathrm{SH} 3\right)$, two proteins that are not associated with disease but whose aggregation behavior is very well characterized. After this treatment, we investigated the effects of the injected aggregates on microglia activation and neuronal viability with respect to control experiments involving injection of the native proteins. These data are also compared with the effects of either the same aggregates or fibrillar $\beta$-amyloid $(\mathrm{A} \beta)$ on the viability of cultured cells (Fezoui et al., 2000) and with previously reported findings (Giovannini et al., 2002) of the effects of injecting into the same region of the brain comparable amounts of fibrillar aggregates of $\mathrm{A} \beta_{1-42}$, the peptide associated with Alzheimer's disease.

\section{Materials and Methods}

Three-month-old (230-250 g) male Wistar rats (Harlan Nossan, Correzzana, Italy) were used in all experiments reported here. The rats were housed in macrolon cages until surgery and maintained on a $12 \mathrm{~h}$ light/ dark cycle at $23^{\circ} \mathrm{C}$. All animal manipulations were performed according to the European Community guidelines for animal care (DL 116/92). The number of animals needed to obtain reliable data were kept to a minimum. No alternatives to in vivo techniques are available for this type of experiment at the present time.

HypF-N and $\mathrm{PI}_{3} \mathrm{SH} 3$ were purified and stimulated to aggregate as reported previously (Bucciantini et al., 2002). Briefly, proteins were incubated for $48 \mathrm{~h}$ at $25^{\circ} \mathrm{C}$ and $0.3 \mathrm{mg} / \mathrm{ml}$ protein concentration (HypF-N) or $1 \mathrm{~h}$ at $30^{\circ} \mathrm{C}$ and $10.0 \mathrm{mg} / \mathrm{ml}\left(\mathrm{PI}_{3} \mathrm{SH} 3\right)$ at $\mathrm{pH} 5.5$, in the presence of $30 \%$ $(\mathrm{v} / \mathrm{v})(\mathrm{HypF}-\mathrm{N})$ or $25 \%\left(\mathrm{PI}_{3} \mathrm{SH} 3\right)$ trifluoroethanol. Under these conditions, only 4- to 8-nm-wide and 20- to 60-nm-short granular aggregates are visible in electron microscopic or atomic force microscopic images (Bucciantini et al., 2002; Relini et al., 2004). Fibrils were grown for 1 month at $37^{\circ} \mathrm{C}$ and $\mathrm{pH} 2.0\left(\mathrm{PI}_{3} \mathrm{SH} 3\right)$ or at $25^{\circ} \mathrm{C}$ and $\mathrm{pH} 5.5(\mathrm{HypF}-\mathrm{N})$. The presence of prefibrillar and fibrillar aggregates in the protein samples was checked by thioflavin $\mathrm{T}$ fluorescence and transmission electron microscopy (data not shown).

The sodium salt of Texas Red STP ester was obtained from Invitrogen (Carlsbad, CA). Antibodies were obtained from Chemicon (Temecula, CA) [anti-choline acetyltransferase (ChAT), polyclonal; anti-neuronalspecific nuclear protein (NeuN), monoclonal; and anti-nitrotyrosine, polyclonal] and from BD Biosciences PharMingen (San Diego, CA) [OX6, anti-major histocompatibility complex II (MHC II) receptor, monoclonal]. Biotinylated secondary antibodies, diaminobenzidine, and the avidin-biotin-peroxidase complex were obtained from Vector Laboratories (Burlingame, CA).

Labeling and detection of HypF-N aggregates. HypF-N aggregates were labeled with Texas Red by adding slowly $10 \mathrm{ml}$ of a $10 \mathrm{mg} / \mathrm{ml}$ Texas Red solution in DMSO to a solution containing $1.0 \mathrm{mg}$ of prefibrillar or fibrillar aggregates dissolved in $0.1 \mathrm{ml}$ of $0.1 \mathrm{M}$ sodium bicarbonate buffer, $\mathrm{pH}$ 8.5. After $1 \mathrm{~h}$ incubation at room temperature with stirring, the reaction was quenched by adding $10 \mathrm{ml}$ of $1.5 \mathrm{M}$ hydroxylamine, $\mathrm{pH}$ 8.5. The medium was exchanged twice with PBS by using a Centricon filter (Millipore, Bedford, MA), and the aggregates were kept at a final protein concentration of $5.0 \mu \mathrm{g} / \mu \mathrm{l}$. Sections of brains injected with the labeled aggregates were examined $24 \mathrm{~h}$ after injection using a Nikon (Tokyo, Japan) Plan Apo $60 \times$ oil immersion objective. Texas Red fluorescence was detected after excitation at $568 \mathrm{~nm}$. A series of optical sections $(512 \times 512$ pixels) $1.0 \mu \mathrm{m}$ in thickness was taken through the brains at $0.8 \mu \mathrm{m}$ intervals. Twenty optical sections for each sample were projected as single composite images by superimposition.

Injection of proteins into the NBM. Fibrillar or prefibrillar aggregates of $\mathrm{HypF}-\mathrm{N}$ or $\mathrm{PI}_{3} \mathrm{SH} 3$ or the monomeric proteins were suspended in $\mathrm{PBS}$ at differing final concentrations (calculated as monomer protein concentration). The $1.0 \mu \mathrm{l}$ aliquots of protein solutions containing either native, prefibrillar, or fibrillar HypF-N were injected into the NBM of the basal forebrain of anesthetized (sodium pentobarbital, $45 \mathrm{mg} / \mathrm{kg}$ ) rats using a Hamilton microsyringe, at the following stereotaxic coordinates (in $\mathrm{mm}$ ): anteroposterior, -0.2 ; lateral, -2.8 from bregma; and $\mathrm{H}, 7.0$ from dura (Paxinos and Watson, 1998). PBS $(1.0 \mu \mathrm{l})$ was injected into the $\mathrm{NBM}$ of the contralateral hemisphere in controls. The injections lasted 3 $\mathrm{min}$, and the microsyringe was left in the place for $5 \mathrm{~min}$ after completing the infusion. All subsequent investigation was performed in tissue taken 1 week after the injection. This was considered a reasonable time period to allow us to detect long-term effects of the injected aggregates in light of their likely persistence in tissue; in addition, this allowed us to compare directly the effects in our system with those reported previously by injecting $A \beta_{42}$ aggregates into the same region of the brain and under identical conditions (Giovannini et al., 2002)

Immunohistochemistry and terminal deoxynucleotidyl transferasemediated biotinylated UTP nick end labeling staining. Rats under deep anesthesia were killed by transcardial perfusion with an ice-cold paraformaldehyde solution $(4.0 \% \mathrm{v} / \mathrm{v}$ in phosphate buffer, $\mathrm{pH} 7.4) 7 \mathrm{~d}$ after the injections to allow quantitative analysis of their effects and comparison with the data obtained previously with injection into the same nucleus of the aggregated $\mathrm{A} \beta$ peptide (Giovannini et al., 2002). The brains were dissected, postfixed for $4 \mathrm{~h}$, cryoprotected in $18 \%$ sucrose solution, and stored at $4^{\circ} \mathrm{C}$ for at least $48 \mathrm{~h}$. They were then frozen at $-80^{\circ} \mathrm{C}$ for at least 
$30 \mathrm{~min}$ and cut in a cryostat through the injected area into $30-\mu \mathrm{m}$-thick coronal sections.

ChAT immunohistochemistry was performed on $30 \mu \mathrm{m}$ cryostat sections. Briefly, free-floating sections were incubated overnight at $4^{\circ} \mathrm{C}$ with the primary antibody at the optimized working dilution in $0.1 \mathrm{~m} \mathrm{PBS,} \mathrm{pH} 7.4$, containing $0.3 \%$ Triton X-100 and $5.0 \mathrm{mg} / \mathrm{ml}$ BSA. On the second day, sections were incubated for $1 \mathrm{~h}$ with the secondary antibody dissolved in $0.1 \mathrm{~mm}$ PBS containing $1.0 \mathrm{mg} / \mathrm{ml}$ BSA; immunostaining was performed by the avidin-biotin system (Vectastain; Vector Laboratories, Burlingame, $\mathrm{CA}$ ) and $\mathrm{DAB}$ plus nickel (DAB kit; Vector Laboratories) as the chromogen. DAB-stained slices were examined using an Olympus Optical (Tokyo, Japan) BX40 microscope, and pictures were taken using an Olympus Optical DP50 digital camera. Monoclonal OX-6 antibodies against MHC class II complex were used to detect activated microglial cells. A polyclonal anti-ChAT antibody was used to detect cholinergic neurons, whereas the total population of neurons was detected by a monoclonal anti-NeuN antibody.

Nitrotyrosine immunohistochemistry was performed on $30 \mu \mathrm{m}$ cryostat sections. Briefly, free-floating sections were incubated overnight at room temperature with the primary antibody (anti-nitrotyrosine polyclonal antibody) at the optimized working dilution in $1 \times$ TBS, pH 7.6, containing $0.1 \%$ Tween 20 and $5.0 \mathrm{mg} / \mathrm{ml} \mathrm{BSA}$. On the second day, the sections were incubated for $1 \mathrm{~h}$ with the secondary antibody dissolved in TBS containing $1.0 \mathrm{mg} / \mathrm{ml} \mathrm{BSA}$; immunostaining was performed by means of the avidin-biotin system (Vectastain; Vector Laboratories) and DAB plus nickel (DAB kit; Vector Laboratories) as the chromogen. DAB-stained slices were examined using an Olympus Optical BX40 microscope, and pictures were taken using an Olympus Optical DP50 digital camera.

Acetylcholinesterase (AChE) histochemistry was performed on $30 \mu \mathrm{m}$ cryostat sections as reported previously (Brofman et al., 2000). Briefly, free-floating sections were washed in PBS and incubated for $30 \mathrm{~min}$ at room temperature with $0.3 \% \mathrm{H}_{2} \mathrm{O}_{2}$ in $50 \mathrm{~mm}$ Tris- $\mathrm{HCl}$ buffer, $\mathrm{pH}$ 7.6, and then for $1 \mathrm{~h}$ in $65 \mathrm{~mm}$ sodium maleate buffer, $\mathrm{pH}$ 6.0, containing 0.05 $\mathrm{mg} / \mathrm{ml}$ acetylthiocholine iodide, $0.1 \mathrm{~mm}$ tetra-isopropyl-pyrophosphatamide, $0.05 \mathrm{~mm}$ potassium ferricyanide, $0.3 \mathrm{~mm} \mathrm{CuSO}_{4}$, and $0.5 \mathrm{~mm}$ sodium citrate. This was followed by a $10 \mathrm{~min}$ incubation in $50 \mathrm{~mm}$ Tris-HCl, pH 7.6, containing $0.3 \%$ ammonium nickel sulfate and $0.04 \%$ diaminobenzidine. Finally, the sections were incubated for $5 \mathrm{~min}$ in $0.03 \% \mathrm{H}_{2} \mathrm{O}_{2}$ (final concentration).

The terminal deoxynucleotidyl transferase (TdT)-mediated biotinylated UTP nick end labeling (TUNEL) assay was performed with the In Situ Cell Death Detection Kit POD (Roche, Mannheim, Germany), according to the instructions of the manufacturer. Briefly, the sections were washed twice with PBS for $15 \mathrm{~min}$, incubated with 3.0\% hydrogen peroxide in methanol for $20 \mathrm{~min}$, and then washed with PBS. The sections were then incubated for $2.0 \mathrm{~min}$ on ice with a permeabilization solution ( $0.1 \%$ Triton X-100 and $0.1 \%$ sodium citrate) and washed with PBS. All of the sections were labeled with the TUNEL reaction mixture for $60 \mathrm{~min}$ at $37^{\circ} \mathrm{C}$ in a humidified atmosphere and in the dark. Negative controls were performed by omitting the enzyme (TdT) from the reaction mixture. Diaminobenzidine-stained sections were viewed under a light microscope.

Congo red staining. Congo red staining was performed on $30 \mu \mathrm{m}$ cry- ostat sections. Briefly, free-floating sections were washed in $\mathrm{H}_{2} \mathrm{O}$ and incubated in a $1 \%$ Congo red solution in $\mathrm{H}_{2} \mathrm{O}$ for $1 \mathrm{~h}$ at room temperature. At the end of incubation, the sections were directly passed into a solution of $\mathrm{Li}_{2} \mathrm{CO}_{3}\left(1.5 \%\right.$ in $\left.\mathrm{H}_{2} \mathrm{O}\right)$ and incubated at room temperature for 2 min with gentle shaking. After an additional $\mathrm{H}_{2} \mathrm{O}$ wash, excess staining was removed by brief immersion in $80 \%$ ethanol, dehydrated, and coverslipped.

Quantitative and statistical analysis. ChAT- and NeuN-positive cells were counted under a $10 \times$ objective lens using a calibrated eyepiece grid. Five sections per animal, standardized in anteroposterior with respect to the injection site and spaced 50-100 $\mu \mathrm{m}$ from each other, were analyzed, and all NeuN- or ChAT-positive cells in the NBM were counted. The total numbers of ChAT-positive and NeuN-positive cells in the injected NBM were compared with those counted in the contralateral, PBSinjected hemisphere. OX-6 immunoreactivity was quantified in DABstained slices as follows: digitized images were transformed into TIFF files and analyzed using Scion for Windows (Scion, Frederick, MD). The gray background was then automatically subtracted from each image, and the area in pixels above the threshold was automatically measured using the same software. Care was taken to maintain the same gray threshold in the images from treated and control slices in each experiment. The area above the threshold in each case was calculated in pixels, and the data were analyzed using Prism 3.0 (GraphPad Software, San Diego, CA). Each experiment was repeated at least three times. Statistical analysis was performed with the same software by using the one-way ANOVA, followed by the Newman-Keuls multiple comparison test. The significance level was set at $p=0.05$. 
A

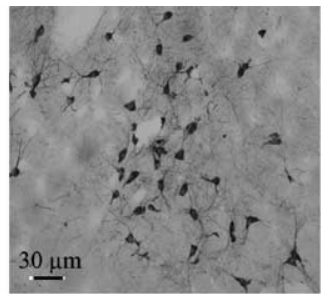

PBS

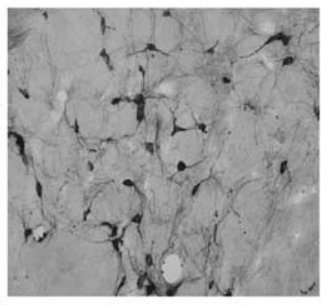

0.01 ng Prefibrillar HypF-N

$\mathrm{C}$

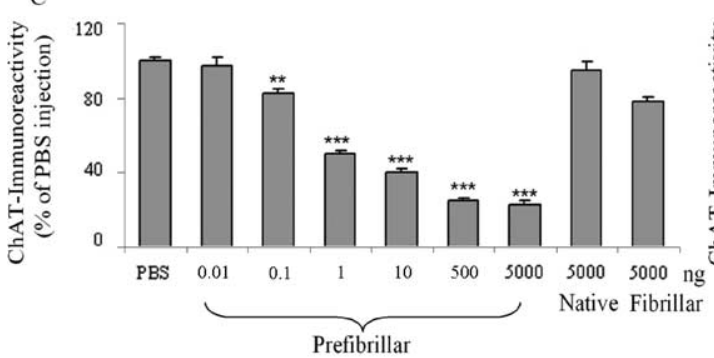

HypF-N

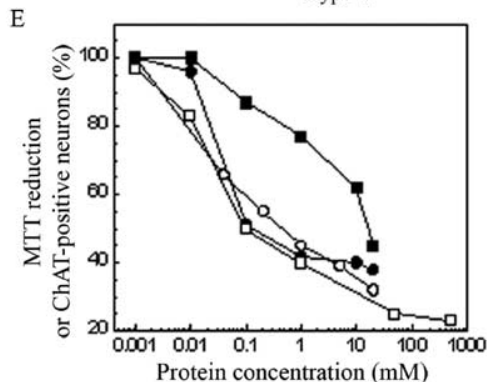

Figure 3. Disappearance of ChAT-positive neurons in the NBM injected with HypF-N or $\mathrm{PI}_{3} \mathrm{SH}$ 3. Cholinergic neurons were visualized by immunohistochemistry as specified in Materials and Methods. $\boldsymbol{A}$, Representative photomicrographs (20X magnification) obtained after injection of $1.0 \mu$ l aliquots of PBS, $5.0 \mu \mathrm{g}$ of HypF-N fibrillar aggregates, and $0.010 \mathrm{ng}$ and $5.0 \mu \mathrm{g}$ of HypF-N prefibrillar aggregates (top left to bottom right, respectively). ChAT immunoreactivity was localized in intensely labeled NBM neurons located at the border between the internal capsule and the globus pallidus. $\boldsymbol{B}$, The same as in $\boldsymbol{A}$ but taken after microinjection of $5.0 \mu \mathrm{g}$ of fibrillar and $5.0 \mu \mathrm{g}$ of prefibrillar $\mathrm{PI}_{3} \mathrm{SH}$. C, D, Quantification of ChAT immunoreactivity in the NBM $7 \mathrm{~d}$ after the injections ( 5 sections per animal). Rats were injected with PBS, $5.0 \mu \mathrm{g}$ of native HypF-N, $5.0 \mu \mathrm{g}$ of fibrillar HypF-N, varying quantities of prefibrillar HypF-N, $5.0 \mu \mathrm{g}$ of native $\mathrm{PI}_{3} \mathrm{SH} 3,5.0 \mu \mathrm{g}$ of fibrillar $\mathrm{PI}_{3} \mathrm{SH} 3$, or $5.0 \mu \mathrm{g}$ of prefibrillar $\mathrm{PI}_{3} \mathrm{SH} 3$ ( $n=6$ for each type of injection). The total neuronal count in the NBM injected with PBS (190 \pm 1.5 , mean \pm SD) was taken as $100 \%$. C , The number of ChAT-positive cells in the NBM injected with $1.0 \mu l$ of PBS containing $5.0 \mu \mathrm{g}(500 \mu \mathrm{m}), 0.50 \mu \mathrm{g}(50 \mu \mathrm{m}), 10.0 \mathrm{ng}(1.00 \mu \mathrm{M}), 1.0 \mathrm{ng}(100 \mathrm{~nm}), 0.100 \mathrm{ng}(10.0 \mathrm{~nm})$, and $0.010 \mathrm{ng}$ (1.0 nм) of prefibrillar HypF-N was reduced by 77\% ( $p<0.001), 75 \%(p<0.001), 60 \%(p<0.001), 50 \%(p<0.001)$, $17 \%(p<0.01)$, and $3 \%(p<0.05)$, respectively, relative to the number of ChAT-positive neurons found in the NBM of the contralateral hemisphere injected with PBS. (Molar concentrations are those of the monomeric HypF-N.) D, The number of ChAT-positive cells in the NBM injected with $5.0 \mu \mathrm{g}$ of native, fibrillar, or prefibrillar $\mathrm{PI}_{3} \mathrm{SH} 3$ was reduced by $\sim 5 \%$ ( $p>0.05), 20 \%(p<0.01)$, and 60\% ( $p<0.001)$, respectively, with respect to the number of positive neurons found in the NBM of the contralateral hemisphere injected with PBS. (Molar concentrations are those of the monomeric $\mathrm{PI}_{3} \mathrm{SH}$.) Statistical analysis on the mean was performed by one-way ANOVA, followed by the Newman-Keuls multiple comparison test $(F=53.03 ; p<0.05) .{ }^{* *} p<0.01$ and ${ }^{* * *} p<0.001$ versus PBS. For details, see Materials and Methods. Scale bar, $30 \mu \mathrm{m}$. $\boldsymbol{E}$, The same data as in $\boldsymbol{C}$ plotted as the concentration of injected HypF-N prefibrillar aggregates against the percentage of ChAT-immunopositive neurons (open squares). The percentages of viable cultured cells (as determined by the MTT test) exposed to differing concentrations of prefibrillar HypF-N (open circles) domain (Bucciantini et al., 2002), $\mathrm{A} \beta_{40}$ (filled squares), or $\mathrm{A} \beta_{42}$ (filled circles) peptides (Fezoui et al., 2000) are also reported.

\section{Results}

We first investigated whether the microinjected HypF-N aggregates could be detected in the basal forebrain NBM $24 \mathrm{~h}$ after the injection by using prefibrillar and fibrillar aggregates labeled with the fluorescent probe Texas Red. Figure 1 shows confocal microscopy images of the NBM from rats treated with $1.0 \mu \mathrm{l}$ of a PBS solution containing $5.0 \mu \mathrm{g}$ of the two types of labeled HypF-N aggregates, together with atomic force microscopy images (Relini et al., 2004) showing the nature of the injected material. In both cases, the fluorescently labeled aggregates are clearly visible in the images, although a higher level of fluorescence was observed in samples injected with the prefibrillar aggregates. This observation may be associated at least in part with a difference in labeling efficiency of the different types of the aggregates, but it is also consistent with the expectation of a greater tendency of the smaller prefibrillar aggregates to be internalized into cells (Bucciantini et al., 2004). Whatever the origin of this difference, however, the results show that both types of aggregates remain in the tissue for sufficient lengths of time to induce substantial effects.

Immunohistochemical analysis performed after injection of aggregates of both $\mathrm{PI}_{3} \mathrm{SH} 3$ and HypF-N reveals the presence of a large number of intensely stained OX-6-immunopositive cells indicative of activated microglia. Therefore, the presence of the aggregates in the NBM induced an inflammatory reaction through the transformation of a significant fraction of microglia from a resting to an activated state at the injection site and along the needle tract (Fig. $2 A, B$ ). In particular, the presence of the prefibrillar forms of both proteins resulted in clusters of activated microglia near the injection site. Quantitative analysis of immunopositive areas indicates a significant increase (up to $\sim 135 \%$ at $5.0 \mu \mathrm{g}$ ) in OX-6 immunoreactivity in tissue injected with prefibrillar aggregates when compared with those injected with PBS, the native proteins, or their fibrillar aggregates (Fig. 2C,D). In the tissue injected with HypF-N, the extent of microglia activation is clearly sensitive to the presence of prefibrillar aggregates because it reaches a plateau value at doses of injected prefibrillar aggregates as low as $0.01 \mathrm{ng}$. No activation was evident when $0.0002 \mathrm{ng}$ of material was injected, however, resulting in a marked dose dependence in the 0.1-10 pg interval (Fig. 2C). A similar pattern of behavior was found after 
injection of $5.0 \mu \mathrm{g}$ of native, prefibrillar, or fibrillar $\mathrm{PI}_{3} \mathrm{SH}$. In particular, a significantly higher level of microglia activation was again found when prefibrillar aggregates were injected relative to that resulting from injection of buffer solution alone or the native protein (Fig. 2 D, bottom). Some activation of microglia by preparations of fibrillar aggregates was also observed for $\mathrm{PI}_{3} \mathrm{SH} 3$, a finding that agrees with previously reported data resulting from the injection of fibrillar $\mathrm{A} \beta_{1-42}$ into the same region of the brain (Giovannelli et al., 1998; Giovannini et al., 2002).

The change in the number of ChAT-positive neurons is a measure of the degree of neuronal stress produced by an insult to cholinergic tissue (Giovannelli et al., 1998; Giovannini et al., 2002). We therefore investigated the effects of the various injections into the NBM on the number of ChAT-positive neurons projecting into the cortex. Measurements were made $7 \mathrm{~d}$ after injection of $5.0 \mu \mathrm{g}$ of native HypF-N, of the same quantity of protein in the form of fibrillar aggregates and of varying amounts $(10.0 \mathrm{pg}$ to $5.0 \mu \mathrm{g})$ of its prefibrillar aggregates. Tissue sections taken $7 \mathrm{~d}$ after injection with prefibrillar or fibrillar HypF-N or $\mathrm{SH} 3$ showed no detectable fluorescence on staining with Congo red; we do not know whether this results from the clearance or internalization into the cells of the injected material or from limitations in the assay performed under the conditions used in the present study. We can be confident, however, that the observations reported here result at least in part, and probably predominantly, from the effects of the initial insult after injection.

In all samples, high staining intensity in the magnocellular neurons shows that ChAT immunoreactivity is present in this region of the brain (Fig. 3A). However, the number of ChATpositive neurons was markedly reduced in a dose-dependent manner (up to $77 \%$ with respect to controls near to the injection site) only in the sections from tissue injected with prefibrillar aggregates (Fig. 3 C). In contrast, injection of the soluble protein did not reduce significantly the number of ChAT-positive neurons relative to those in the NBM of the contralateral hemisphere injected with PBS (Fig. 3C). Similar results were obtained in a second set of experiments performed by injecting $5.0 \mu \mathrm{g}$ of native, fibrillar, or prefibrillar $\mathrm{PI}_{3} \mathrm{SH} 3$ into the NBM (Fig. $3 B$ ). A marked reduction of the number of ChAT-positive neurons was again seen with the prefibrillar aggregates (Fig. 3D). The close similarity between the effects of the injection of aggregates of $\mathrm{PI}_{3} \mathrm{SH} 3$ and of HypF-N again suggests that cell dysfunction associated with the presence of early amyloid aggregates is the result of a common, perhaps generic, mechanism. The microscopic analysis of the immunostaining reaction with nitrotyrosine antibody did not reveal a significant increase in oxidative stress in the NMB injected compared with the contralateral hemisphere (data not shown). In addition, the cholinergic innervation around the site of injection was revealed by immunostaining for AChE, a general marker for cholinergic fibers. It is clear that cell staining was reduced in the nuclei injected with prefibrillar proteins with respect to the nuclei injected with PBS or with the same proteins in their fibrillar forms (Fig. 4). The lower AChE immunopositivity in the nuclei injected with prefibrillar aggregates agrees with their lower ChAT immunopositivity.

The data on cell dysfunction reported in Figure $3 C$ were plotted to show the relationship between the number of ChATpositive neurons and the concentration of injected prefibrillar HypF-N and in Figure $3 E$ are compared with previous doseresponse data obtained after exposure of cultured cells to differing concentrations of prefibrillar HypF-N (Bucciantini et al., 2002) or fibrillar $\mathrm{A} \beta_{40 / 42}$ associated with Alzheimer's disease (Fezoui et al., 2000). Although a quantitative comparison of these

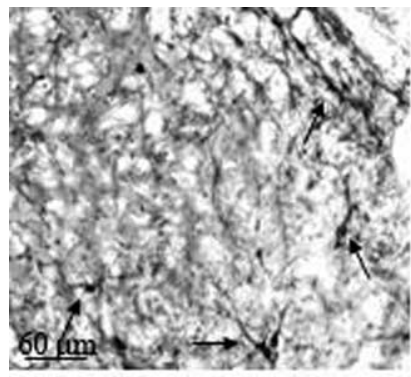

PBS

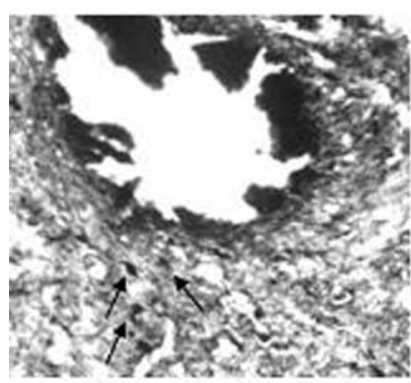

5000 ng Fibrillar SH3

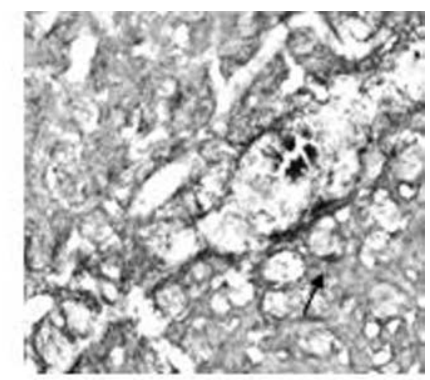

$0.01 \mathrm{ng}$ Prefibrillar HypF-N

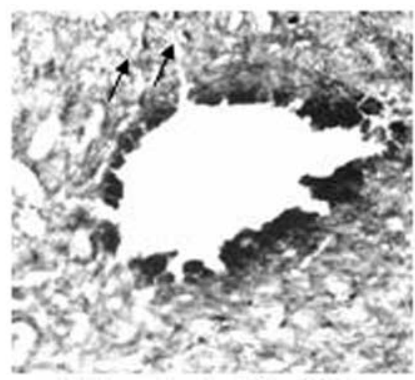

$5000 \mathrm{ng}$ Prefibrillar SH3
Figure 4. Reduction in the levels of $\mathrm{AChE}$ in the site of microinjection of $\mathrm{HypF}-\mathrm{N}$ and $\mathrm{PI}_{3} \mathrm{SH} 3$ aggregates in the NBM. AChE was visualized by histochemistry and DAB staining. Representative photomicrographs (10X magnification) obtained after injection of $1.0 \mu$ l aliquots of PBS, $0.01 \mathrm{ng}$ of HypF-N fibrillar aggregates, $5.0 \mu \mathrm{g}$ of fibrillar, and of $5.0 \mu \mathrm{g}$ of prefibrillar $\mathrm{PI}_{3} \mathrm{SH} 3$. The arrows indicate the AChE-positive fibers. For additional details, see Materials and Methods. Scale bar, $60 \mu \mathrm{m}$.

two sets of experiments in different systems is not possible, it is clear that these plots show marked similarities to each other. This observation suggests that the toxic effects observed in the present study are likely to arise directly from the interaction of the aggregates with cholinergic neuronal cells rather than from indirect effects such as glia activation. From the data shown in Figure $3 C$, an $\mathrm{IC}_{50}$ value of $\sim 1.0 \mathrm{ng}$ and a lower limit for the toxicity of injected HypF-N prefibrillar aggregates of $\sim 0.1 \mathrm{ng}$ can be estimated for the conditions used here. This analysis also shows that the concentration range in which the toxicity associated with the prefibrillar aggregates is dose-dependent $(0.1-500 \mathrm{ng})$ is higher than that giving rise to activation of the microglia $(0.1-10 \mathrm{pg})$ (Fig. 2). This finding, together with the evident dose dependence of cholinergic neuron dysfunction, supports further the idea that the latter results specifically from the presence of the prefibrillar aggregates rather than being merely a consequence of the inflammatory reaction associated with microglia activation.

The total number of neuronal cells in the NBM sections was determined by quantifying the number of cells that stained with an antibody specific to $\mathrm{NeuN}$, a typical neuronal marker, $7 \mathrm{~d}$ after injection of $5.0 \mu \mathrm{g}$ of HypF-N aggregates (Fig. 5A). The number of neurons was decreased by $31 \pm 3.5 \%(p<0.01)$ and $27 \pm$ $5.5 \%(p<0.01)$ with respect to saline-injected controls when prefibrillar or fibrillar aggregates were injected, respectively. Such a decrease, although statistically highly significant, is much lower than the corresponding loss of ChAT immunoreactivity. We also determined the number of neurons that had undergone apoptosis in the injected areas of the NBM $7 \mathrm{~d}$ after exposure to the various aggregates using a TUNEL assay (Fig. 5B). Moderately higher numbers of TUNEL-positive cells were present in the samples taken from rats injected with $5.0 \mu \mathrm{g}$ of prefibrillar HypF-N or $\mathrm{PI}_{3} \mathrm{SH} 3$ than from rats injected with $5.0 \mu \mathrm{g}$ of fibrillar $\mathrm{PI}_{3} \mathrm{SH} 3$ or 
A
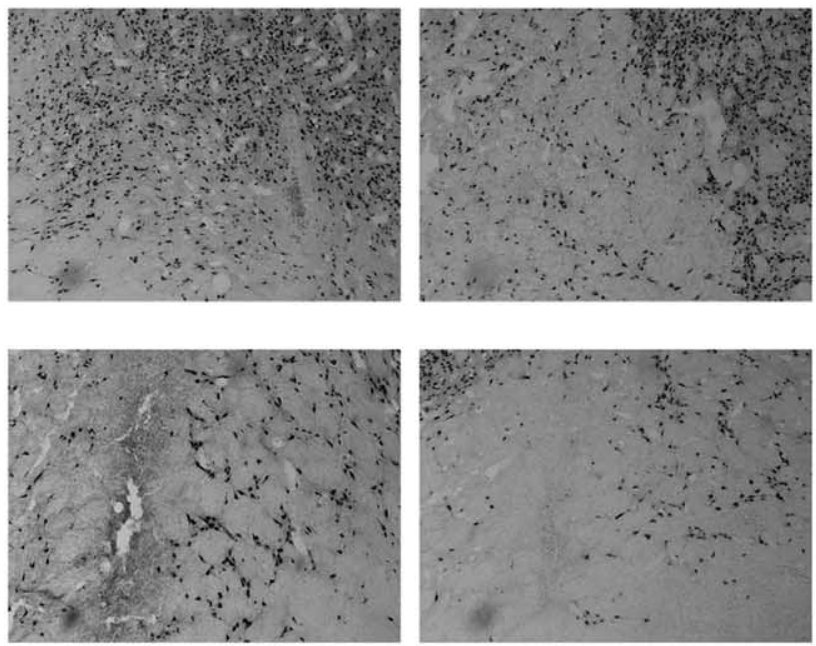

吉 1

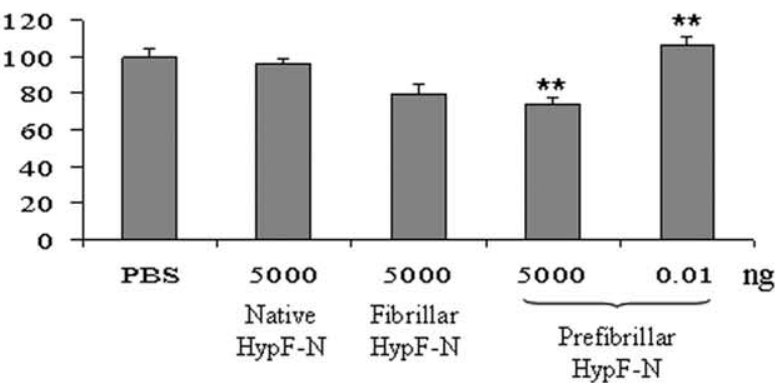

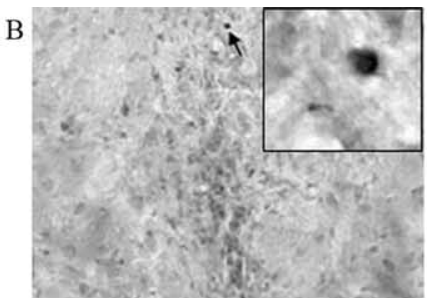

PBS

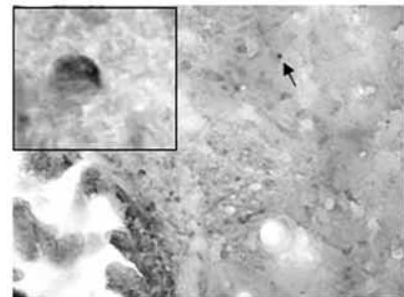

10 ng Prefibrillar HypF-N

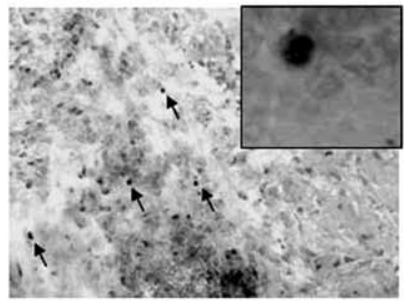

5000 ng Prefibrillar SH3

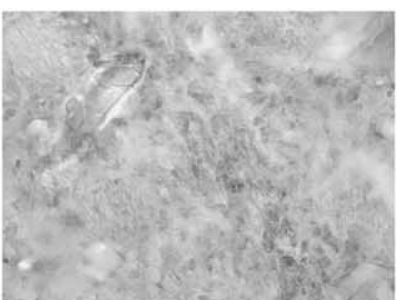

Negative Control

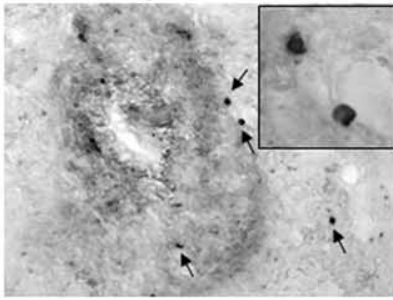

5000 ng Prefibrillar HypF-N

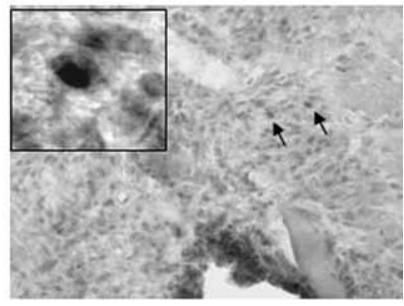

5000 ng Fibrillar SH3

Figure 5. Total number of neurons in the NBM $7 \mathrm{~d}$ after microinjecting HypF-N or $\mathrm{Pl}_{3} \mathrm{SH} 3$ aggregates. $A$, Number of neurons in the NBM injected with PBS (top left), monomeric (top right), prefibrillar (bottom right), or fibrillar (bottom left) HypF-N as determined by quantifying the cells stained with an anti-NeuN antibody (10× magnification in each image). ${ }^{* *} p<0.01$ versus PBS. $B$, Microinjection of large amounts of HypF-N or $\mathrm{Pl}_{3} \mathrm{SH} 3$ prefibrillar aggregates causes more extensive DNA fragmentation than does injection of very low amounts of prefibrillar aggregates of HypF- $\mathrm{N}$ or of high amounts of $\mathrm{Pl}_{3} \mathrm{SH} 3$ fibrillar aggregates as shown by TUNEL staining ( $40 \times$ magnification in each case). Additional details are given in Materials and Methods.

with $10 \mathrm{ng}$ of prefibrillar HypF-N. The reduced number of apoptotic cells did not allowed us to perform a detailed quantitative analysis of cell death; however, it must be noted that, in the injected tissue, the increase in the number of apoptotic neurons was much less evident than the decrease in ChAT immunoreactivity shown in Figure 3. Finally, oxidative stress was not evident in the neurons near the injected area, as determined by immunoassaying the presence of nitrotyrosine (data not shown). These observations suggest that cholinergic (and possibly other) neurons in the NBM are indeed stressed by the injected aggregates, as revealed by the strongly reduced expression of ChAT, but a single injection is not sufficient to reduce by the same extent the total number of neurons. Our data agree with previously reported findings indicating that, in rats injected with a single dose of $A \beta_{42}$ peptide aggregates, at 6 months after surgery, the aggregates had become essentially amorphous in character and ChAT immunoreactivity had recovered completely (Giovannelli et al., 1998).

\section{Discussion}

In previous studies, we have shown that prefibrillar aggregates of HypF-N and $\mathrm{PI}_{3} \mathrm{SH}_{3}$ can be highly toxic to cultured neuronal and fibroblast cells even at low levels $(2.0 \mu \mathrm{M})$ (Bucciantini et al., 2002, 2004). The present findings show that the prefibrillar aggregates result in cell dysfunction also when they are microinjected into rat brains. Interestingly, the low levels of toxicity found with the fibrillar species could easily arise from tiny amounts of prefibrillar aggregates present in the samples either as residual material or produced from partial dissociation of the monomers from fibrils (Carulla et al., 2005). The reduction of ChAT-positive neurons in the NBM injected with $5.0 \mu \mathrm{g}$ of fibrillar HypF-N is, for example, comparable with that found with 0.10 ng of prefibrillar HypF-N (Fig. 3C); it would be surprising if such a small quantity of prefibrillar species were not to be present in the injected fibrillar samples. The data reported here also indicate that microinjection of both $\mathrm{PI}_{3} \mathrm{SH} 3$ and HypF-N prefibrillar aggregates into the NBM results in a much higher level of neuronal stress than that produced by comparable amounts of $\mathrm{A} \beta_{1-42}$ fibrillar aggregates (Giovannelli et al., 1998; Giovannini et al., 2002). The injection of $5.0 \mu \mathrm{g}$ of fibrillar $A \beta_{1-42}$ resulted in a reduction of the number of ChAT-positive neurons by $\sim 40 \%$ with respect to the PBS-injected NBM in the contralateral hemisphere (Giovannini et al., 2002). We found a similar reduction when quantities of prefibrillar HypF-N in the $0.10-1.0 \mathrm{ng}$ range were injected into the NBM, whereas the loss of ChAT-positive neurons after injection with $5.0 \mu \mathrm{g}$ of prefibrillar HypF-N or $\mathrm{PI}_{3} \mathrm{SH} 3$ was $\sim 77$ and $60 \%$, respectively. However, our data do not exclude the recently proposed idea (Wogulis et al., 2005) that at least some of the toxicity could be caused by the nucleationdependent polymerization of residual monomeric protein present in the samples of prefibrillar aggregates injected into the NBM in the time period preceding that at which measurements are made.

Our findings indicate that a noncontinuous exposure to toxic aggregates may stress cholinergic neurons without severe cellular impairment (as shown by the apparent lack of significant oxida- 
tive stress) or extensive cell death, contrary to what happens with cultured cells. This result agrees with previous data from experiments in which A $\beta$ fibrils (Giovannini et al., 2002) or oligomers (Cleary et al., 2005) were injected into rat brains. Although it was beyond the scope of the present study to follow the fate of the aggregates themselves after injection, it is likely that the toxic species will be converted into other forms of aggregates or cleared by the protective mechanisms present in living systems (Stefani and Dobson, 2003) and hence that more severe cell damage will result from repeated or continuous exposure to toxic aggregates. A possible explanation of the different behavior of cultured and tissue cells can be the presence in cerebral tissue of glia cells as well as other protective mechanisms favoring the suppression of the toxicity of the aggregates, their clearance, or their structural modification into less toxic species. The latter idea is supported by recent data showing that $\mathrm{PI}_{3} \mathrm{SH} 3$ fibrils are in dynamic equilibrium with the monomers with a recycling half-time of $2-20 \mathrm{~d}$ (Carulla et al., 2005).

Recently, homogeneous preparations of small spherical aggregates of $\mathrm{A} \beta_{1-40}$ and $\mathrm{A} \beta_{1-42}$ have been reported to induce neurodegeneration in primary cultures of cholinergic neurons at concentrations as low as $0.35 \mathrm{~nm}$ for $\mathrm{A} \beta_{1-42}$ (100 times higher for $\mathrm{A} \beta_{1-40}$ ) (Hoshi et al., 2003). These concentrations are not much lower than the lowest level (10 nM) of injected HypF-N prefibrillar aggregates that we found to result in cell dysfunction in our experiments. $\mathrm{A} \beta$ peptide oligomers have been identified in the frontal cortex of victims of Alzheimer's disease at much higher levels than in age-matched healthy subjects (Gong et al., 2003); a specific $\mathrm{A} \beta_{42}$ oligomeric assembly has also been found in brains of Tg2576 mice expressing an amyloid precursor protein variant linked to a familial form of Alzheimer's disease (Lesné et al., 2006). Finally, a recent report shows that natural oligomers of $A \beta$ peptides injected into the lateral ventricle of rat brains are able to affect specifically and reversibly cognitive function (Cleary et al., 2005). Our results, therefore, suggest that the early aggregates of proteins not associated with neurodegenerative diseases are able to stress neuronal cells similarly to oligomeric aggregates of the $\mathrm{A} \beta$ peptides associated with Alzheimer's disease.

These findings extend considerably a variety of previous observations that small aggregates of peptides and proteins, whether associated with amyloid disease or not, display much higher toxicity to cells in culture than do mature fibrils (Conway et al., 2000; Nilsberth et al., 2001; Bucciantini et al., 2002; Walsh et al., 2002; Kayed et al., 2003; Kranenburg et al., 2003; Sirangelo et al., 2004; Walsh and Selkoe, 2006). Because recent experiments have shown that most, perhaps all, polypeptides can form amyloid aggregates under suitable conditions (Guijarro et al., 1998; Chiti et al., 2001; Fändrich and Dobson, 2002) (for review, see Dobson, 2003), we suggest that the generic ability to convert into a misfolded and aggregationprone state gives any peptide or protein the potential to transform from a normal functional state into one that can inflict significant, possibly fatal, damage to the living organism in which it is present. Given that such species must be continuously generated during the folding and unfolding of proteins, the results also reveal the remarkable efficiency of the multiple mechanisms that normally protect cells against such species. They also provide evidence to support the hypothesis (for review, see Dobson, 2003; Stefani and Dobson, 2003) that the gradual impairment of such mechanisms in old age could be a primary feature in the onset and development of a range of disorders, including many of the most highly debilitating neurodegenerative diseases.

\section{References}

Brofman FC, Moechars D, Van Leuven F (2000) Acetylcholinesterasepositive fiber deafferentation and cell shrinkage in the septohippocampal pathway of aged amyloid precursor protein London mutant transgenic mice. Neurobiol Dis 7:152-168.

Bucciantini M, Giannoni E, Chiti F, Baroni F, Formigli L, Zurdo J, Taddei N, Ramponi G, Dobson CM, Stefani M (2002) Inherent toxicity of aggregates implies a common mechanism for protein misfolding diseases. $\mathrm{Na}$ ture 416:507-511.

Bucciantini M, Calloni G, Chiti F, Formigli L, Nosi D, Dobson CM, Stefani M (2004) Pre-fibrillar amyloid protein aggregates share common features of cytotoxicity. J Biol Chem 279:31374-31382.

Bucciantini M, Rigacci S, Berti A, Pieri L, Cecchi C, Nosi D, Formigli L, Chiti F, Stefani M (2005) Patterns of cell death triggered in two different cell lines by HypF-N prefibrillar aggregates. FASEB J 19:437-439.

Carulla N, Caddy GL, Hall DR, Zurdo J, Gairi M, Felix M, Giralt E, Robinson CV, Dobson CM (2005) Molecular recycling within amyloid fibrils. Nature 436:584-588.

Chiti F, Bucciantini M, Capanni C, Taddei N, Dobson CM, Stefani M (2001) Solution conditions can promote formation of either amyloid protofilaments or mature fibrils from the HypF N-terminal domain. Protein Sci 10:2541-2547.

Cleary JP, Walsh DM, Hofmeister JJ, Shankar GM, Kuskowski MA, Selkoe DJ, Ashe KH (2005) Natural oligomers of the amyloid- $\beta$ protein specifically disrupt cognitive function. Nat Neurosci 8:79-84.

Conway KA, Lee SJ, Rochet JC, Ding TT, Harper JD, Williamson RE, Lansbury Jr PT (2000) Acceleration of oligomerization not fibrillization is a shared property of both alpha-synuclein mutations linked to early-onset Parkinson's disease. Implication for pathogenesis and therapy. Proc Natl Acad Sci USA 97:571-576.

Dobson CM (2003) Protein folding and misfolding. Nature 426:884-890.

Fändrich M, Dobson CM (2002) The behaviour of polyamino acids reveals an inverse side chain effect in amyloid structure formation. EMBO J 21:5682-5690.

Fezoui Y, Hartley DM, Walsh DM, Selkoe DJ, Osterhout JJ, Teplow DB (2000) A de novo designed helix-turn-helix peptide forms nontoxic amyloid fibrils. Nat Struct Biol 7:1095-1099.

Giovannelli L, Scali C, Faussone-Pellegrini MS, Pepeu G, Casamenti F (1998) Long-term changes in the aggregation state and toxic effects of $\beta$-amyloid injected into the rat brain. Neurochemistry 87:349-357.

Giovannini MG, Scali C, Prosperi C, Bellucci A, Vannucchi MG, Rosi S, Pepeu G, Casamenti F (2002) $\beta$-amyloid-induced inflammation and cholinergic hypofunction in the rat brain in vivo: involvement of the p38MAPK pathway. Neurobiol Dis 11:257-274.

Goldberg AL (2003) Protein degradation and protection against misfolded or damaged proteins. Nature 426:895-899.

Goldberg MS, Lansbury PT (2000) Is there a cause-and-effect relationship between alpha-synuclein fibrillization and Parkinson's disease? Nat Cell Biol 2:E115-E119.

Gong Y, Chang L, Viola KL, Lacor PN, Lambert MP, Finch CE, Krafft GA, Klein WL (2003) Alzheimer's disease-affected brain: presence of oligomeric A $\beta$ ligands (ADDSLs) suggest a molecular basis for reversible memory loss. Proc Natl Acad Sci USA 100:10417-10422.

Guijarro JL, Sunde M, Jones JA, Campbell ID, Dobson CM (1998) Amyloid fibril formation by an SH3 domain. Proc Natl Acad Sci USA 95:4224-4228.

Hoshi M, Sato M, Matsumoto S, Noguchi A, Yasutake K, Yoshida N, Sato K (2003) Spherical aggregates of $\beta$-amyloid (amylospheroid) show high neurotoxicity and activate tau protein kinase I/glycogen synthase kinase$3 \beta$. Proc Natl Acad Sci USA 100:6370-6375.

Huff ME, Balch WE, Kelly JW (2003) Pathological and functional amyloid formation orchestrated by the secretory pathway. Curr Opin Struct Biol 13:674-682.

Kayed R, Head E, Thompson JL, McIntire TM, Milton SC, Cotman CW, Glabe CG (2003) Common structure of soluble amyloid oligomers implies common mechanisms of pathogenesis. Science 300:486-489.

Kayed R, Sokolov Y, Edmonds B, McIntire TM, Milton SC, Hall JE, Glabe CG (2004) Permeabilization of lipid bilayers is a common conformationdependent activity of soluble amyloid oligomers in protein misfolding diseases. J Biol Chem 279:46363-46366.

Kelly J (1998) Alternative conformation of amyloidogenic proteins and their multi-step assembly pathways. Curr Opin Struct Biol 8:101-106. 
Kranenburg O, Kroon-Batenburg LM, Reijerkerk A, Wu YP, Voest EE, Gebbink MF (2003) Recombinant endostatin forms amyloid fibrils that bind and are cytotoxic to murine neuroblastoma cells in vitro. FEBS Lett 539:149-155.

Lesné S, Koh MT, Kotilinek L, Kayed R, Glabe CG, Yang A, Gallagher M, Ashe $\mathrm{KH}$ (2006) A specific amyloid- $\beta$ protein assembly in the brain impairs memory. Nature 440:352-357.

Merlini G, Westermark P (2004) The systemic amyloidoses: clearer understanding of the molecular mechanisms offers hope for more effective therapies. J Intern Med 255:159-178.

Nilsberth C, Westlind-Danielsson A, Eckman CB, Condron MM, Axelman K, Forsell C, Stenh C, Luthman J, Teplow DB, Younkin SG, Naslund J, Lannfelt L (2001) The "arctic" APP mutation. (E693G) causes Alzheimer's disease by enhanced $A \beta$ protofibril formation. Nat Neurosci 4:887-893.

Paxinos G, Watson G (1998) The rat brain in stereotaxic coordinates. New York: Academic.

Relini A, Torrassa S, Rolandi R, Gliozzi A, Rosano C, Canale C, Bolognesi M, Plakoutsi G, Bucciantini M, Chiti F, Stefani M (2004) Monitoring the process of HypF fibrillization and liposome permeabilization by protofibrils. J Mol Biol 338:943-957.

Selkoe DJ (2003) Folding proteins in fatal ways. Nature 426:900-904.

Selkoe DJ (2004) Cell biology of protein misfolding: the examples of Alzheimer's and Parkinson's diseases. Nat Cell Biol 6:1054-1061.
Serpell LC, Sunde M, Benson MD, Tennent GA, Pepys MB, Fraser PE (2000) The protofilament substructure of amyloid fibrils. J Mol Biol 300:1033-1039.

Sirangelo I, Malmo C, Iannuzzi C, Mezzogiorno A, Bianco MR, Papa M, Irace G (2004) Fibrillogenesis and cytotoxic activity of the amyloid-forming apomyoglobin mutant W7FW14F. J Biol Chem 279:13183-13189.

Sitia R, Braakman I (2003) Quality control in the endoplasmic reticulum protein factory. Nature 426:891-894.

Stefani M, Dobson CM (2003) Protein aggregation and aggregate toxicity: new insights into protein folding, misfolding diseases and biological evolution. J Mol Med 81:678-699.

Tycko R (2004) Progress towards a molecular-level structural understanding of amyloid fibrils. Curr Opin Struct Biol 14:96-103.

Walsh DM, Selkoe DJ (2004) Oligomers on the brain: the emerging role of soluble protein aggregates in neurodegeneration. Protein Pept Lett 11:213-228.

Walsh DM, Klyubin I, Fadeeva JV, Cullen WK, Anwyl R, Wolfe MS, Rowan MJ, Selkoe DJ (2002) Naturally secreted oligomers of amyloid beta protein potently inhibit hippocampal long-term potentiation in vivo. Nature 416:535-539.

Wogulis M, Wright S, Cunningham D, Chilcote T, Powell K, Rydel RE (2005) Nucleation-dependent polymerization is an essential component of amyloid-mediated neuronal cell death. J Neurosci 25:1071-1080. 